\title{
Assessment of the High Heat Flux Performance of European DEMO Divertor Mock-ups
}

\author{
Henri Greuner, ${ }^{\mathrm{a}}$ B. Böswirth ${ }^{\mathrm{a}}$, K. Hunger ${ }^{\mathrm{a}}$, A. Khan ${ }^{\mathrm{a}}$, T. R. Barrett ${ }^{\mathrm{b}}$, F. Gallayc, \\ M. Richou', E. Visca ${ }^{\mathrm{d}}$, A.v. Müller ${ }^{\mathrm{a}}$ and J.H. You ${ }^{\mathrm{a}}$ \\ ${ }^{a}$ Max Planck Institute for Plasma Physics, Boltzmannstr. 2, D-85748 Garching, Germany \\ ${ }^{b}$ CCFE, Culham Science Centre, Abingdon OX14 3DB, United Kingdom \\ ${ }^{c}$ CEA, IRFM, F-13108 Saint Paul Lez Durance, France \\ ${ }^{d}$ ENEA, Department of Fusion and Technology for Nuclear Safety and Security, Frascati, Italy
}

Corresponding author: henri.greuner@ipp.mpg.de

\begin{abstract}
In the framework of the DEMO divertor project an extensive R\&D program has been carried out to develop advanced design concepts for hot water cooled divertor targets. These plasma-facing components are made of $\mathrm{W}$ monoblocks as plasma facing material bonded on CuCrZr cooling tubes. They are designed to allow a reliable DEMO operation of two hour long pulses up to a $20 \mathrm{MW} / \mathrm{m}^{2}$ maximum heat flux. Considering the current experiences of the qualification of ITER divertor components, the operation at significantly higher neutron fluence, the longer required lifetime, and the coolant temperature of $150^{\circ} \mathrm{C}$ are challenges for design and manufacturing.

The aim of the performed HHF tests is to support the identification of the most promising design concepts for further development. Eight different types of monoblock mock-ups were designed and manufactured by the involved research groups. These mock-ups were assessed by HHF examination in the test facility GLADIS at IPP Garching. The HHF tests were focused on $20 \mathrm{MW} / \mathrm{m}^{2}$ loading with $500-1000$ cycles using hot water cooling to simulate slow thermal transients in DEMO. In screening tests heat fluxes up to $32 \mathrm{MW} / \mathrm{m}^{2}$ were applied to study the performance of the components against single thermal events exceeding the expected heat flux limits.

This paper gives an overview of the main results obtained from the HHF tests of about 45 components. The microscopic examination after loading analyses recrystallization effects and investigates the $\mathrm{W} / \mathrm{Cu}$ interfaces in more detail.
\end{abstract}

Keywords: Tungsten, Divertor, Monoblock, Plasma-Facing Components, DEMO, High Heat Flux Tests

author's email: henri.greuner@ipp.mpg.de 


\section{Introduction}

The highly heat loaded divertor target plates are one of the most challenging components of a future demonstrational power plant (DEMO). In the EUROfusion DEMO divertor project (PPPT-WP-DIV) an extensive R\&D program has been carried out to develop advanced design concepts for hot water cooled divertor targets [1][2]. These plasma-facing components (PFCs) made of W blocks as a plasma-facing material (PFM) bonded on CuCrZr cooling tubes should allow a reliable DEMO operation for $2 \mathrm{~h}$ long pulses at nominal $10 \mathrm{MW} / \mathrm{m}^{2}$ and maximum heat flux excursions up to 20 $\mathrm{MW} / \mathrm{m}^{2}$ during 300 cycles of slow transient events shorter than $10 \mathrm{~s}$ [3]. Compared to ITER ( 0.1 dpa after 4 years of nuclear operation [4], the significantly higher neutron dose of $4 \mathrm{dpa}$ in W armour, $13 \mathrm{dpa}$ in the divertor cooling tubes during two full power operation years [3], the longer required lifetime and the operation at higher coolant temperature of $150^{\circ} \mathrm{C}$, are challenges exceeding the current extent of experience of the world-wide development of W monoblock components for the ITER divertor [4]. The expected neutron embrittlement and reduction of thermal conductivity of W and $\mathrm{Cu}$ based materials requires the development of concepts for the specific operation in DEMO. The development of innovative target designs started on the basis of the ITER monoblock design as a reference. More details about the design and the thermal performance of the ITER monoblock concept can be found in references [5][6]. The R\&D activities take into account advanced structural analysis, code based design, the implementation of new highperformance materials, as well as verification by high heat flux (HHF) tests.

In the first phase of WP-DIV (2014 -2018), 8 different concepts, including so-called flat tile design (bonding of a W tile on a heat sink), were developed and their HHF performance was assessed. Mock-ups with different block sizes and W/Cu interfaces were designed and fabricated by the EUROfusion members CCFE, CEA, ENEA, KIT and IPP (Garching). The variation of outer W block dimensions allows for the study of the influence of the monoblock size on the plastic fatigue and fracture behavior. The width ranged from 23 to28 mm and the axial length from 4 to12 mm, respectively. All W blocks were provided by A.L.M.T. (Japan) and AM\&T (PR China). The cooling tubes of the mock-

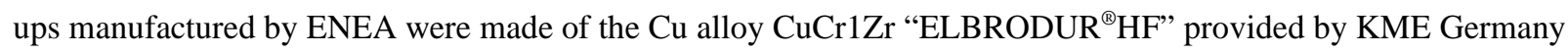
$\mathrm{GmbH}$. The mock-ups were manufactured by hot radial pressing performed by ENEA, or brazing and hot isostatic pressing performed by different European manufacturers.

To adapt the mismatch of thermal expansion between $\mathrm{W}$ and CuCrZr different approaches were applied to improve the W/Cu interface by variation of $\mathrm{Cu}$ interlayer thickness between 0.1 to $1 \mathrm{~mm}$ or the application of W/Cu graded interlayers. The thermal break concept reduces temperature and stress concentration at the cooling pipe and finally, the development of a $\mathrm{W}$ fibre reinforced $\mathrm{Cu}$ tube improves the thermo-mechanical properties of the cooling tube. Information in more detail about the design rationales, the material interfaces and the structure of the project are published elsewhere [3], [7]. Further details of the design, manufacturing and testing of $1^{\text {st }}$ phase mock-ups are given in the literature, e.g. [8], [9], [10], [9], [11], [12]. Results of ultra-sonic inspection, which was performed before and after HHF loading, are published in reference [13].

The second project phase was focused on both, the improvement of manufacturing technologies and the reduction of design variations. A uniform W block geometry (23 mm width, $12 \mathrm{~mm}$ axial length and $8 \mathrm{~mm}$ armor thickness) was used for all mock-ups. All mock-ups were equipped with swirl tapes (twist ratio =2). In this paper we discuss the latest HHF test results from the $2^{\text {nd }}$ phase which were focused on $20 \mathrm{MW} / \mathrm{m}^{2}$ loading with $500-1000$ cycles using hot water cooling to simulate fatigue due to slow thermal transients in DEMO. In screening tests, heat fluxes up to $32 \mathrm{MW} / \mathrm{m}^{2}$ 
were applied to study the performance of the components against single thermal events exceeding the predicted heat flux limits during operation.

\section{Approach of HHF testing procedure}

The aim of the HHF tests is the evaluation of the thermal performance of different target concepts, the experimental validation of numerical predicted thermo-mechanical behaviour under DEMO relevant heat load and cooling conditions and finally the selection of the most promising concepts for further development.

The two-step procedure according to reference [8] was complemented by additional screening up to $32 \mathrm{MW} / \mathrm{m}^{2}$. The first step was performed for each component as an "initial quality assessment” of the delivered components,

- $\quad$ screening up to $25 \mathrm{MW} / \mathrm{m}^{2}$, at cold water $\left(20^{\circ} \mathrm{C}\right.$ inlet, $1 \mathrm{MPa}$ static pressure, $12 \mathrm{~m} / \mathrm{s}$ velocity),

- 100 cycles at $10 \mathrm{MW} / \mathrm{m}^{2}$ as low cycle test.

After having passed this assessment without damage, the hot water, high pressure tests $\left(130^{\circ} \mathrm{C}\right.$ inlet, 4 MPa pressure, 16 $\mathrm{m} / \mathrm{s}$ velocity) were performed as the second step:

- $\quad$ Screening from 6 to $20 \mathrm{MW} / \mathrm{m}^{2}$, each component,

- 100 cycles at $20 \mathrm{MW} / \mathrm{m}^{2}$, each component,

- $500(1000)$ cycles at $20 \mathrm{MW} / \mathrm{m}^{2}$ as low cycle fatigue, one component of each concept at least.

Since a number of concepts passed these tests with comparable good results, the heat load was increased up to the thermal limit of a safe heat transfer to the coolant. The aim was to study the integrity of the component after such single overloading events. To apply significant higher heat fluxes it was necessary to perform these tests at $20^{\circ} \mathrm{C}$ cold cooling water with $16 \mathrm{~m} / \mathrm{s}$ velocity.

\section{High heat flux loading}

\subsection{Heat transfer conditions and loading limits}

The components should ensure a safe heat transfer in the regime of sub-cooled boiling for both, the cold water- and hot water cooling. The following heat flux limits were set in consideration of the geometry of the loaded components and the safety margin against the onset of critical heat flux (CHF), which was calculated according to TONG75-CEA [14]:

- $28 \mathrm{MW} / \mathrm{m}^{2}$ for the $1^{\text {st }}$ step cold water tests,

- $22 \mathrm{MW} / \mathrm{m}^{2}$ for the $2^{\text {nd }}$ step hot water tests (similar to the DEMO limits [9]) and

- $32 \mathrm{MW} / \mathrm{m}^{2}$ for the cold water overload tests.

A more detailed view on the consequences of $20^{\circ} \mathrm{C}$ cold and $130^{\circ} \mathrm{C}$ hot water cooling related to the $150^{\circ} \mathrm{C}$ design water temperature of the DEMO divertor is given in reference [8].

\subsection{Loading and surface temperature measurement}


All mock-ups were installed and tested individually in GLADIS [15]. The mock-ups were installed in the horizontal direction, normal to the beam axis. This resulted in an 8 degree inclination of the loaded surface to the vertical plane. The actively water cooled mock-ups reached the thermal equilibrium after $\sim 7 \mathrm{~s}$ loading, meaning a constant temperature and stress profile across the component. Therefore, all cyclic tests were performed with $10 \mathrm{~s}$ loading followed by 50 or 80 s cooling, respectively. The applied hydrogen neutral beam (Gaussian profile with 150 mm FWHM) ensures a simultaneous and homogeneous heating of all monoblocks of the mockups shown in Fig. 1. The calorimetrically measured absorbed power compared to the calculated incident power is in an agreement within $\pm 5 \%$. The surface temperature of the exposed mock-ups was measured with one- and two-colour pyrometers as well as monitored by an infrared camera Infratec VARIOCAM HD. The two-colour pyrometer ( $\varnothing 8 \mathrm{~mm}$ focus, $\lambda=1.4-1.75 \mu \mathrm{m}$, temperature range $500-1700{ }^{\circ} \mathrm{C}$ ) was used as reference for the emissivity $(\varepsilon)$ determination of the one-colour pyrometer ( $\varnothing 22 \mathrm{~mm}$ focus, $\lambda=2.0-2.2 \mu \mathrm{m}$, temperature range $350-3500^{\circ} \mathrm{C}$ ) and the IR camera. A crucial point of reliable surface temperature measurements of such W components is the surface modification during HHF cyclic loading (see Fig. 4) and the resulting change of emissivity during cyclic loading. The long term fluctuation of the beam power density distribution is in a range of $\pm 5 \%$ as confirmed by cooling water calorimetry. A constant $\varepsilon=0.3$ was applied for all presented one-color pyrometer data. Only for measurements during screening are the obtained pyrometer data up to $3000{ }^{\circ} \mathrm{C}$ reliable within an accuracy of $\pm 5 \%$.

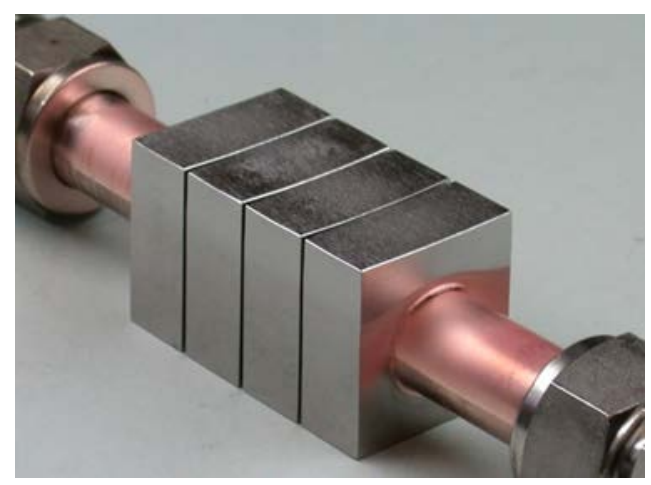

Fig. 1: Example of a HHF tested W monoblock mock-up. The mock-up is equipped with 23 x $12 \times 28 \mathrm{~mm}^{3} \mathrm{~W}$ blocks provided by A.L.M.T (JP) or AM\&T (CN).

\section{Results and discussion}

4000 cycles at $10 \mathrm{MW} / \mathrm{m}^{2}$ cold water cooling and 8000 cycles at $20 \mathrm{MW} / \mathrm{m}^{2}$ hot water cooling have been applied on 45 components up to now. No unexpected serious defect occurred during cyclic testing of the various target concepts in total equipped with 252 monoblocks.

The results of the monoblock concepts tested in GLADIS as shown in Table 1 are now discussed.

\begin{tabular}{|l|r|r|r|}
\hline Design concept & $\begin{array}{r}\text { Design by, } \\
\text { Reference }\end{array}$ & $\begin{array}{r}\text { Cycles at } 20 \mathrm{MW} / \mathrm{m}^{2} \\
\text { hot water cooling }\end{array}$ & $\begin{array}{r}32 \mathrm{MW} / \mathrm{m}^{2}, 5 \text { cycles } \\
\text { cold water cooling }\end{array}$ \\
\hline
\end{tabular}




\begin{tabular}{|l|l|l|l|}
\hline $\begin{array}{c}\text { ITER like, 1 mm Cu } \\
\text { interlayer }{ }^{1)}\end{array}$ & ENEA [9] & 500, no visible failure & no visible failure ${ }^{5)}$ \\
\hline $500 \mu \mathrm{m}$ FGM & CEA [10] & 500, no visible failure & No component available \\
\hline $300 \mu \mathrm{m}$ Cu interlayer & ENEA [7] & 500, no visible failure & no visible failure ${ }^{5)}$ \\
\hline $100 \mu \mathrm{m}$ Cu interlayer & ENEA [7] & 500, no visible failure ${ }^{2)}$ & no visible failure ${ }^{5)}$ \\
\hline $20 \mu \mathrm{m}$ Cu-HIP & CEA [10] & $300^{3)}$ & Not performed \\
\hline $20 \mu \mathrm{m}$ FGM & CEA [10] & $300^{4)}$ & Not performed \\
\hline Thermal break & CCFE [11] & 500, no visible failure & Surface melting ${ }^{6)}$ \\
\hline Wf Cu composite tube & IPP [12] & 1000, no visible failure & no visible failure ${ }^{5)}$ \\
\hline
\end{tabular}

Table 1: Summary of investigated monoblock concepts of $2^{\text {nd }}$ phase. The term "no visible failure" means that the surface temperature is stable during HHF loading and no indication of debonding is visible.

1) Two different $\mathrm{W}$ material delivered by A.L.M.T. and AT\&M

2) cooling down of one block delayed

3) debonding of two blocks started after 132 cycles

4) debonding of two blocks started after 122 cycles

5) additionally loaded with 100 cycles at $25 \mathrm{MW} / \mathrm{m}^{2}$

6) one pulse, melting was expected from FEM prediction

For the seven different monoblock components the equilibrium surface temperatures during cyclic fatigue tests at 20 $\mathrm{MW} / \mathrm{m}^{2}$ and $130^{\circ} \mathrm{C}$ water temperature are shown in Fig.2. Despite the various W/Cu interface designs, ranging from CCFE thermal break to 1mm thick pure Cu applied for "ENEA ITER like” and up to $100 \mu \mathrm{m}$ Cu for "ENEA $100 \mu \mathrm{m}$ $\mathrm{Cu}$ ", the surface temperature variation is in the range of only $\pm 5 \%$ related to FEM calculated temperature of an ITER like geometry. The results of the seven tested mockups subjected to $20 \mathrm{MW} / \mathrm{m}^{2}$ cyclic loads with hot water cooling illustrate the high thermal performance and the robustness of the individual designs. 


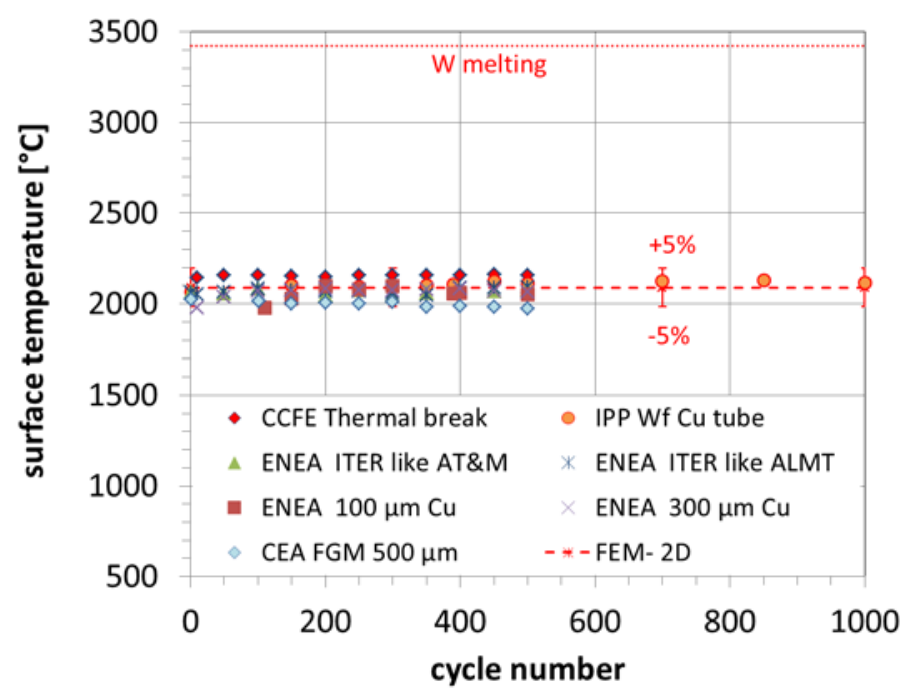

Fig. 2. Surface temperature of selected concepts depending on the cycle number for $20 \mathrm{MW} / \mathrm{m}^{2}$ heat flux at $130{ }^{\circ} \mathrm{C}$, 4 $\mathrm{MPa}, 16 \mathrm{~m} / \mathrm{s}$ cooling water. The presented temperatures were pyrometrically measured in the centre of mock-ups.

The limits of the concept against thermal overloading can be concluded from overload tests up to $32 \mathrm{MW} / \mathrm{m}^{2}$. We applied five $10 \mathrm{~s}$ pulses at each loading step. Fig.3. summarizes the measured surface temperatures of these tests. As mentioned above the temperatures were measured with the one-colour pyrometer at constant $\varepsilon=0.3$. The accuracy of the measurement at high temperature is reduced due to the strong temperature dependence of the emissivity. As seen in Fig. 3 , the temperatures above $3000{ }^{\circ} \mathrm{C}$ were measured too low. Tungsten surface melting was reached at $32 \mathrm{MW} / \mathrm{m}^{2}$ heat flux on the thermal break mock-up as predicted from the FEM calculation. To reduce the risk of loss of stable cooling conditions this test was only performed for the CCFE thermal break where the highest surface temperatures and the lowest heat flux peaking at the cooling tube were expected.

It should be noted that the results of these cold water tests cannot be applied directly to the operation conditions in DEMO. As mentioned in section 3.1, the expected onset of $\mathrm{CHF}$ is much earlier for $150^{\circ} \mathrm{C}$ DEMO cooling water conditions in comparison to the cold water tests performed in this study. Therefore, for heat fluxes exceeding 25 $\mathrm{MW} / \mathrm{m}^{2}$ a collapse of heat transfer and a sudden melting of cooling tube is expected. Such a loss of coolant event should be strictly avoided. 


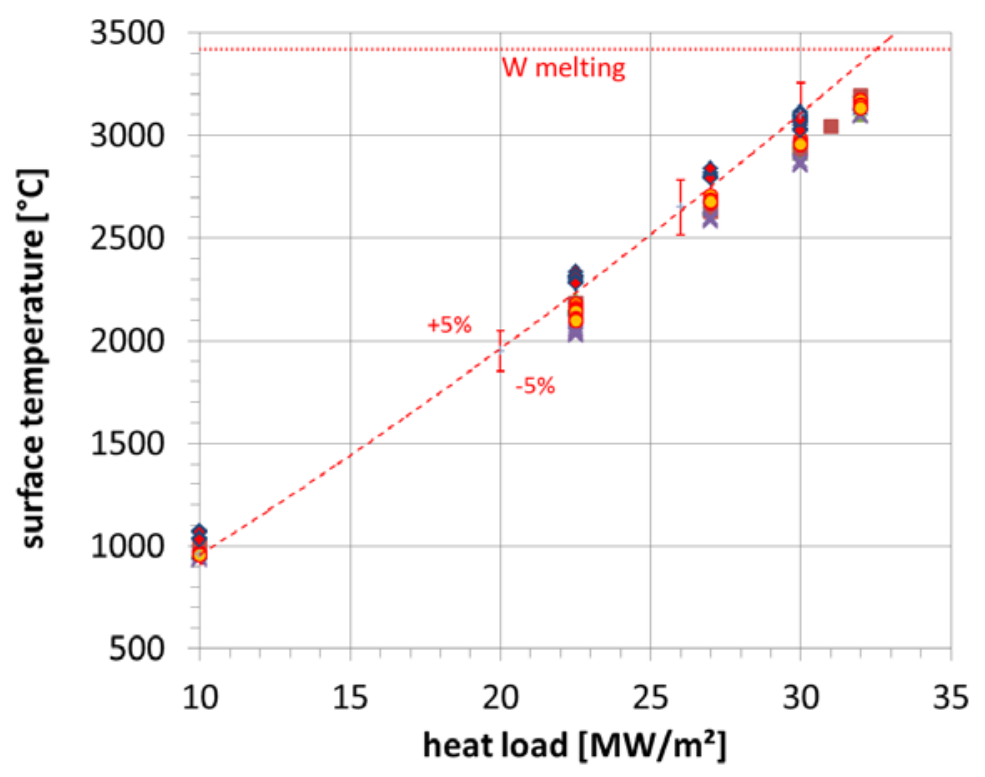

Fig. 3. Surface temperature of selected concepts depending on heat flux at $20^{\circ} \mathrm{C}, 1 \mathrm{MPa}, 16 \mathrm{~m} / \mathrm{s}$ cooling water velocity. The temperatures were pyrometrically measured in the centre of mock-ups. The applied constant emissivity causes deviations at temperatures above $3000^{\circ} \mathrm{C}$. The symbols of the data are the same as in Fig. 2.

\subsection{W surface investigation after 500 cycles at $20 \mathrm{MW} / \mathrm{m}^{2}$}

No cracks in the $\mathrm{W}$ armour occurred during the cyclic tests of all components as shown in Fig. 4. The surface temperature of $\sim 2050^{\circ} \mathrm{C}$ applied for 25 min total equilibrium time resulted in a strong change of surface morphology due to recrystallization and thermo-mechanical effects. Compared to $28 \mathrm{~mm}$ wide $\mathrm{W}$ blocks, the change of the block geometry to a barrel-like shape due to accumulation of plastic deformation is suppressed for all tested $23 \mathrm{~mm}$ wide blocks. The observed geometry change could mostly be interpreted as a cyclic accumulation of creep strain and creepplasticity interaction as described in reference [16]. We attribute the observed suppression to the smaller W block width of $23 \mathrm{~mm}$ compared to results of HHF testing of $28 \mathrm{~mm}$ wide ITER small scale mock-ups. The occurrence of deep W cracks and so-called "self-castellation" effects for higher cycle numbers at $20 \mathrm{MW} / \mathrm{m}^{2}$ loading have been published in a number of references for $28 \mathrm{~mm}$ wide W blocks [17], [18], [19].

The quantitative assessment of such size effects is of importance for the divertor component design. A computational study about the thermal and structural impact of monoblock size on the plastic fatigue and fracture behavior of an ITER-type tungsten divertor target is published in reference [16]. The authors show that the trend of J-integral assessment for the larger monoblock dimensions implies that a monoblock geometry with the width of $28 \mathrm{~mm}$ will likely be subjected to high risk of armor cracking, resulting in deep cracks up to the $\mathrm{W} / \mathrm{Cu}$ interface. For $23 \mathrm{~mm}$ wide $\mathrm{W}$ blocks there is a significantly lower risk of deep cracking in the armor and plastic fatigue in the copper interlayer. 

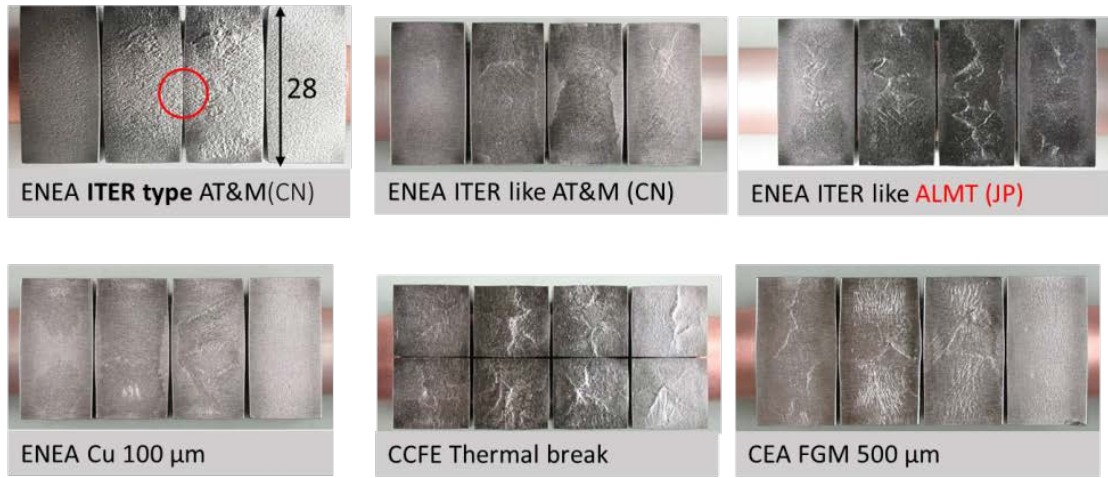

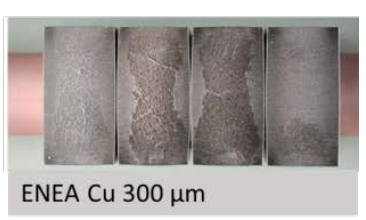

ENEA Cu $300 \mu \mathrm{m}$

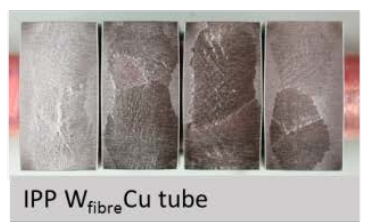

Fig 4. View on loaded surface of the components after 500 cycles $20 \mathrm{MW} / \mathrm{m}^{2}$ at hot water cooling. The circle marks the closed $0.5 \mathrm{~mm}$ manufacturing gap of the $28 \mathrm{~mm}$ wide ENEA ITER like equipped with W made by AT\&M.

\subsection{Microscopic examination after $20 \mathrm{MW} / \mathrm{m}^{2}$ cycling}

The microscopic examination of all mock-ups loaded with 500 cycles at $20 \mathrm{MW} / \mathrm{m}^{2}$ hot water cooling did not reveal any $\mathrm{W}$ cracks or delaminations of the W/Cu interlayer. Fig. 5 a -b show as examples metallographic cross-sections of the loaded and unloaded part of block 3 of the ENEA ITER like mock-up made with W provided by A.L.M.T. Fig. $5 \mathrm{c}$ shows a corresponding cross-section of an ENEA ITER like mock-up equipped with W blocks made by AT\&M. The effects of recrystallization and grain growth are very similar for both $\mathrm{W}$ materials provided by A.L.M.T. and AT\&M, respectively. Recrystallization started at $1200 \pm 50^{\circ} \mathrm{C}$ according to the FEM predicted temperature distribution. This temperature is in good agreement with data published in the literature. From optical microscopy, it appears that the loaded surface is dominated by the formation of extremely large grains in contrast to the deeper laying recrystallized layers. However, from electron backscatter diffraction (EBSD) analysis, it is observed that this region actually consists of smaller grains (typical size between 50 to $100 \mu \mathrm{m}$ ) with nearly the same orientation. Therefore, the colour in the optical micrograph is identical in a large area. The grain size distribution is similar in the recrystallized part and the colder or unloaded part, respectively. However, the texture of the material due to the manufacturing disappears.

The $\mathrm{Cu}$ interlayer in the loaded part of the component was subjected to peak temperatures of about $450-500{ }^{\circ} \mathrm{C}$ during the cyclic tests. Strong grain growth is observed compared to the lower unloaded part of the component as shown in Fig 5. The grain size and orientation of the CuCrZr cooling tube seem unaffected from the performed HHF tests. 

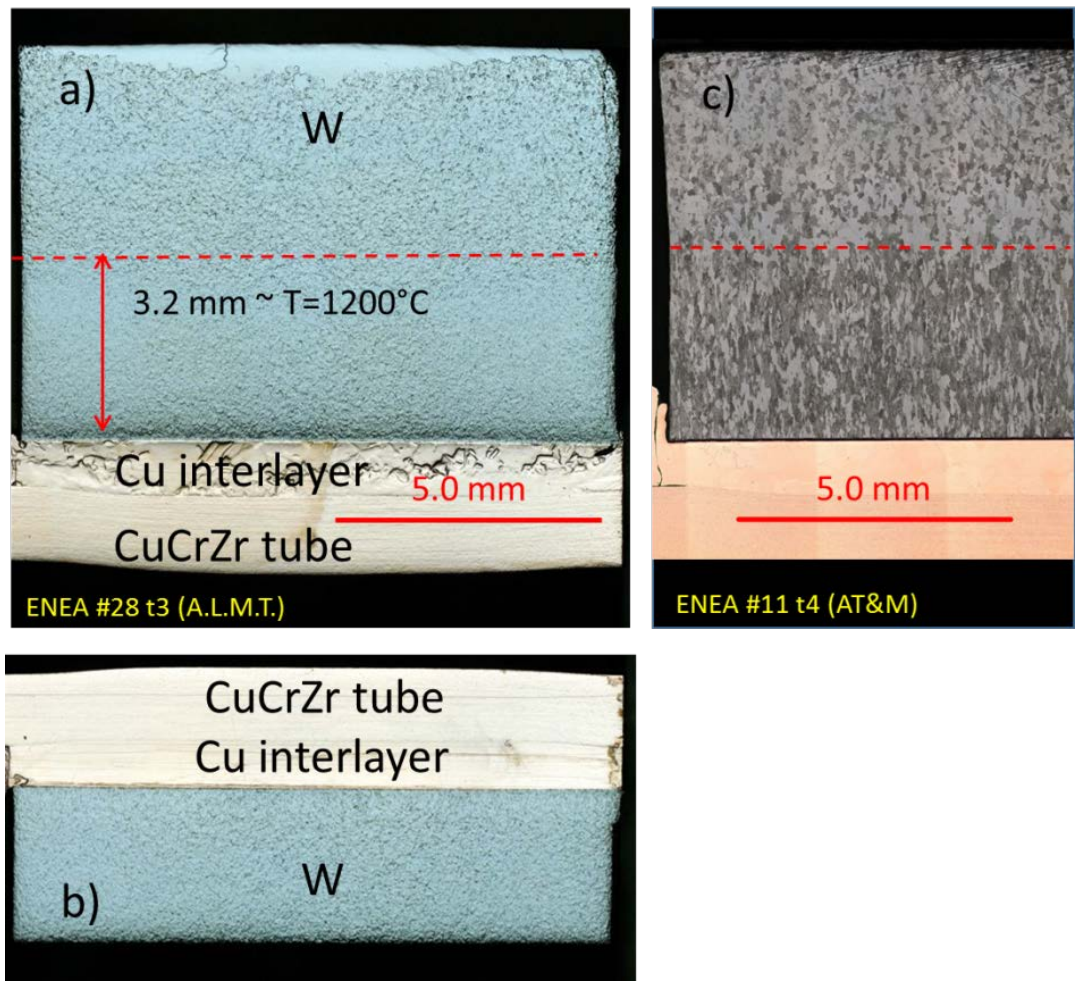

Fig. 5. Cross-sections of two mock-ups after 500 cycles $20 \mathrm{MW} / \mathrm{m}^{2}$ loading at hot water cooling. The dashed line in a) and c) marked the beginning of recrystallized material. Image a) shows the upper half and the loaded surface on top of a W block provided by A.L.M.T. The lower unloaded part is shown in b). Image c) shows the loaded upper part of a W block made by AT\&M.

\subsection{Microscopic examination after surface melting at $32 \mathrm{MW} / \mathrm{m}^{2}$ loading}

The aim of HHF loading up to surface melting was both, to study the effect of re-solidification of W and to investigate the integrity of the component after such single overloading events. Fig. 6 shows the homogenous surface melting which corresponds very well to the heat flux and the resulting temperature distribution. From the loading history, it can be assumed that the pronounced transition to recrystallized $\mathrm{W}$ occurred during 5 pulses at $30 \mathrm{MW} / \mathrm{m}^{2}$ and the following single pulse at $32 \mathrm{MW} / \mathrm{m}^{2}$. During this loading sequence the corresponding temperatures at the W/Cu bonding ( 900 $\left.{ }^{\circ} \mathrm{C}\right)$ and a maximal temperature of about $470{ }^{\circ} \mathrm{C}$ at the CuCrZr tube did not lead to remarkable damage of these materials. With the exception of the change of shape of the W blocks due to loss of molten material and the formation of small resolidification cracks, no structural damage of the component occurred.

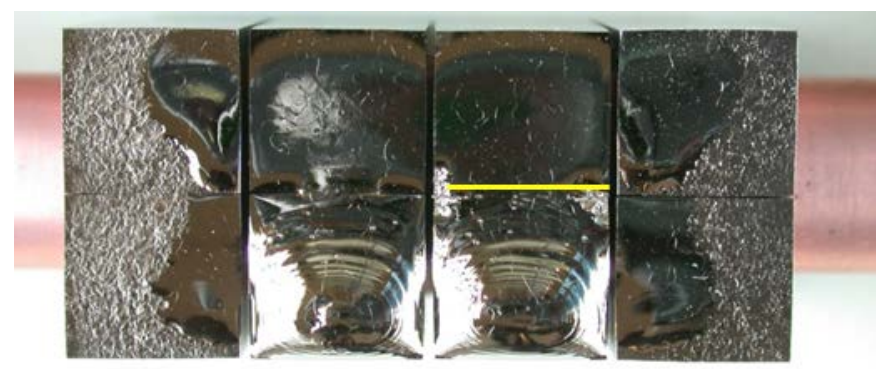


Fig 6. Surface melting of the CCFE Thermal break component occurred at a single $32 \mathrm{MW} / \mathrm{m}^{2} 10 \mathrm{~s}$ heat pulse. The yellow line marks the position of cross-section shown in Fig. 7.

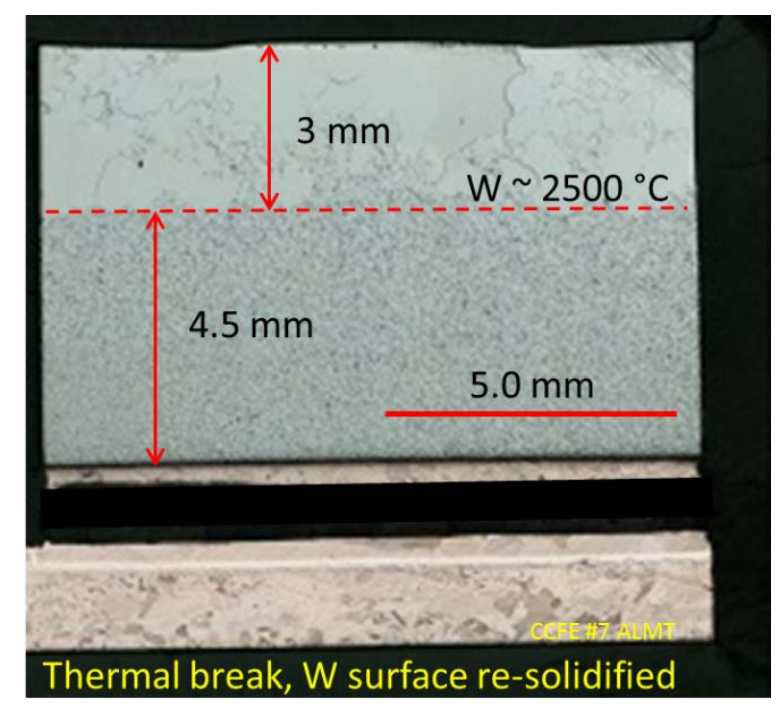

Fig 7. Cross-section of a W monoblock after $32 \mathrm{MW} / \mathrm{m}^{2} 10 \mathrm{~s}$ heat pulse resulting in surface melting. A pronounced resolidification and recrystallization of a $3 \mathrm{~mm}$ layer is visible. The cross-section cuts the interspace of the thermal break made of spokes. Therefore no Cu material is seen in this region.

\section{Summary and conclusion}

As mentioned in the introduction, this paper does not give a final assessment of all HHF tests performed in the frame of the WP-DIV project on water cooled DEMO divertor target concepts. In total 4000 cycles at $10 \mathrm{MW} / \mathrm{m}^{2}$ cold water cooling and 8000 cycles at $20 \mathrm{MW} / \mathrm{m}^{2}$ hot water cooling were applied on 45 mockups with the following results:

- Five concepts, including three variations of "ITER like" have survived the cyclic testing procedure and loading up to $32 \mathrm{MW} / \mathrm{m}^{2}$. Concepts with thin $\mathrm{W} / \mathrm{Cu}$ interface are not robust against fatigue during cyclic loading.

- $\quad$ No unexpected serious defect occurred during testing of the various W monoblock concepts.

- $\quad$ No cracking occurred in W blocks delivered by both manufacturers, AT\&M and A.L.M.T.

- The recrystallization behavior of $\mathrm{W}$ provided by both manufactures is very similar, recrystallization started at $1200^{\circ} \mathrm{C}$.

- $\quad$ The HHF tests confirmed the FEM predictions concerning temperature distribution, accumulation of plastic deformation and creep

- $\quad$ The hot radial pressing of the CuCrZr tubes is a reliable manufacturing technique.

Following this investigation, it can be concluded: 
The tested concepts of DEMO water-cooled divertor targets are able to withstand a $20 \mathrm{MW} / \mathrm{m}^{2}$ cyclic heat load. The WP-DIV program achieved an important R\&D progress in the development of DEMO divertor targets made of W monoblock PFCs. The HHF tests have confirmed that the water-cooled W monoblock concept in general is close to thermal limits. The power load capability cannot be increased significantly, however, a reduction of stress is possible by the application of optimized designs. The HHF tests confirmed that the smaller $23 \mathrm{~mm}$ width W monoblocks are more resistant to cracking in comparison to larger monoblocks.

\section{Acknowledgments}

“This work has been carried out within the framework of the EUROfusion Consortium and has received funding from the Euratom research and training programme 2014-2018 and 2019-2020 under grant agreement No 633053. The views and opinions expressed herein do not necessarily reflect those of the European Commission.”

\section{References}

[1] Romanelli F., Fusion Electricity: A Roadmap to the Realization of Fusion Energy 2012 EFDA

[2] Federici G., Bachmann C, Biel W., et al., Fusion Engineering and Design 2016 109-111 1464-1474

[3] You J. H., et al., Fusion Engineering and Design 2016 109-111 1598-1603

[4] Villari R., et al., Fusion Engineering and Design 201388 2006- 2010

[5] Hirai T., Panayotis S., Barabash V., et al., Nuclear Materials and Energy 20169 616-622

[6] Riccardi B, et al., Fusion Engineering and Design 2019 https://doi.org/10.1016/j.fusengdes.2019.02.120

[7] You J. H., Visca E., Barrett T., et al., Nuclear Materials and Energy 201816 1-11

[8] Greuner H., Böswirth B., Barrett T.R., et al., Fusion Engineering and Design 2019 https://doi.org/10.1016/j.fusengdes.2018.12.021

[9] Crescenzi F., Greuner H., Roccella, S, et al., Fusion Engineering and Design $2017124432-436$

[10] Richou M., Gallay F., Boeswirth B., et al., Physica Scripta 2017 T170 014022

[11] Fursdon M., Barrett, T., Domptail, F., et al., Physica Scripta 2017 T170 014042

[12] von Mueller A., Ewert D., Galatanu A., et al., Fusion Engineering and Design 2017124 455-459

[13] Dose G., et al., Fusion Engineering and Design 2019 https://doi.org/10.1016/j.fusengdes.2019.01.102

[14] Schlosser J., Update of Thermal Hydraulic Data Base, CEA Cadarache, PCO/95-12

[15] Greuner H., et al., Journal of Nuclear Materials 2007 367-370 1444-1448

[16] Li M. and You J.-H., Nuclear Materials and Energy 201814 1-7

[17] Hirai T., et al. Journal of Nuclear Materials 2015463 1248-1251

[18] Panayotis S., et al. Nuclear Materials and Energy 201712 200-204

[19] Pintsuk G. et al. Fusion Engineering and Design 201388 1858-1861

[20] Schatt W. and Worch H., Werkstoffwissenschaft 2003 Willey-VCH, Weinheim 